Pablo Fuentes R., En búsqueda de huellas, indicios y señales: una mirada meticulosa a tres personajes anarquistas de la tetralogía narrativa de Manuel Rojas - In search of traces, evidence and signs: a meticulous look at three anarchist characters from Manuel Rojas' narrative tetralogy, Revista Izquierdas, 25, octubre 2015, IDEA-USACH, ISSN 0718-5049, pp. 120-142

\title{
En búsqueda de huellas, indicios y señales: una mirada meticulosa a tres personajes anarquistas de la tetralogía narrativa de Manuel Rojas
}

\author{
In search of traces, evidence and signs: a meticulous look at three anarchist \\ characters from Manuel Rojas' narrative tetralogy
}

Pablo Fuentes Retamal*

\begin{abstract}
Resumen: En el presente artículo se estudian tres personajes de la tetralogía narrativa de Manuel Rojas con el propósito de develar las identidades de quienes sirvieron de inspiración al narrador para dar forma a la ficción novelesca. Dado que la diégesis rojiana se sitúa temporalmente en las primeras décadas del siglo $\mathrm{XX}$, durante la vigencia de la Ley Jaramillo (disposición jurídica que faculta a la autoridad para expulsar del país a todo militante de ideas contrarias a la seguridad interior del Estado) el narrador asume ciertos resguardos y camufla al escritor González Vera, el poeta Gómez Rojas, y el médico Juan Gandulfo entre las páginas del relato. Este procedimiento narrativo, mantiene a salvo las identidades y proyectos de estos militantes anarquistas, pues evidenciar sus nombres y actividades supondría una denuncia en los aparatos de orden y seguridad.
\end{abstract}

Palabras clave: Manuel Rojas, tetralogía narrativa, Ley Jaramillo, personajes anarquistas, pormenores.

\begin{abstract}
This article examines three characters from Manuel Rojas' narrative tetralogy for the purpose of revealing some people's identities whose inspiration was useful for the narrator to shape the fiction in novels. Since Rojas' diegesis is placed temporarily in de first decades of the twentieth century during the validity of Jaramillo's Law (legal regulation which empowers authority to exile every activist who may have ideas that are contrary to the state security) the narrator accepts some protection and camouflages the writer González Vera, the poet Gómez Rojas, and the doctor Juan Gandulfo between the pages of the story. This narrative procedure keeps these anarchists' ideas and projects safe, considering that, making their names and activities evident would represent a problem for the state security apparatus.
\end{abstract}

Keywords: Manuel Rojas, narrative tetralogy, Jaramillo's Law, anarchist characters, minutiae.

\footnotetext{
Chileno. Profesor de Estado en Castellano, Licenciado en Educación, Magister en Literatura Latinoamericana. Actualmente, candidato a Doctor en Literatura Latinoamericana de la Universidad de Concepción, p.fuentes.retamal@gmail.com
} 
Pablo Fuentes R., En búsqueda de huellas, indicios y señales: una mirada meticulosa a tres personajes anarquistas de la tetralogía narrativa de Manuel Rojas - In search of traces, evidence and signs: a meticulous look at three anarchist characters from Manuel Rojas' narrative tetralogy, Revista Izquierdas, 25, octubre 2015, IDEA-USACH, ISSN 0718-5049, pp. 120-142

Porque hay cosas que para lograrlas han de andar ocultas, y de proclamarse en lo que son, levantarían dificultades demasiado recias para alcanzar sobre ellas el fin.

José Martí, Carta de despedida a Manuel Mercado

Ricardo Piglia sostiene en Critica y ficción (1986) que cada relato posee un punto ciego cuyo secreto sólo un lector único será capaz de descubrir (2001, p.138). Para mantener este enigma a salvo el narrador debe proceder de modo semejante a un criminal, es decir, cifrando, tal como si fuesen delitos, los materiales políticos e ideológicos de la narración.

Para develar el enigma que esconde la narración el crítico argentino sugiere realizar una lectura a modo de detectives, esto es pesquisando huellas, indicios y señales capaces de develar los enigmas que el narrador ha preferido camuflar entre las páginas del relato; en palabras más sencillas, el convite es a valorar en el ejercicio escritural un proceder criminal, en tanto que en la lectura las indagatorias de un investigador policial (pp.14-5).

Al estimar junto a Piglia que la Literatura es 'el arte de lo implícito', resulta interesante prestar atención a los personajes de la tetralogía rojiana cuyas verdaderas identidades han sido puestas a resguardo. Por consiguiente, en este artículo se invita a desarrollar una lectura meticulosa capaz de identificar huellas, indicios y señales que develen las identidades de los sujetos que se esconden tras la ficción de los personajes rojianos.

$\mathrm{Si}$, tal como sugiere Piglia, procedemos a modo de detectives, hallaremos pruebas suficientes para demostrar que tras el peluquero Gutiérrez se esconde la ficcionalización del escritor González Vera; que la personalidad del poeta Daniel se condice con la identidad de José Domingo Gómez Rojas; y los proyectos de don Juan concuerdan con los intereses del médico Juan Gandulfo.

Estimamos que el narrador rojiano mantiene en resguardo las identidades de aquellos sujetos que inspiraron a sus personajes, a causa de las prohibiciones políticas de comienzos del siglo XX, época en la que se sitúa temporalmente la tetralogía rojiana. Recordemos que durante gobierno del Presidente José Luis Sanfuentes (1915-1920) se promulga la Ley Jaramillo ${ }^{1}$, disposición jurídica que entrega concesiones a la autoridad para expulsar del país a propagandistas de ideas perniciosas, inmorales o contrarias a la seguridad interior del Estado. El abogado Carlos Vicuña ilustra el funcionamiento de esta disposición legal, señalando lo siguiente:

El procedimiento es muy rápido: la policía aprehende sin más trámite al expulsado, y lo pone en la frontera, como esté. Ningún recurso cabe contra este atropello en que la víctima no tiene cómo hacerse oír. Lo único que se le permite es reclamar ante la Corte

\footnotetext{
${ }^{1}$ La Ley Jaramillo recibe este nombre, a causa del diputado Fernando Jaramillo, quien la propuso al parlamento.
} 
Pablo Fuentes R., En búsqueda de huellas, indicios y señales: una mirada meticulosa a tres personajes anarquistas de la tetralogía narrativa de Manuel Rojas - In search of traces, evidence and signs: a meticulous look at three anarchist characters from Manuel Rojas' narrative tetralogy, Revista Izquierdas, 25, octubre 2015, IDEA-USACH, ISSN 0718-5049, pp. 120-142

Suprema, la cual, fallando en conciencia y sin forma de juicio, está autorizada para enervar el decreto de expulsión. (2002, p.109)

De acuerdo al historiador Ricardo Donoso, la Ley Jaramillo incorpora al léxico judicial chileno el término 'subversivo', empleándose para designar a cuantos "promovían el mejoramiento de las condiciones de las clases trabajadoras o miraban con simpatía su causa" (en Vitale, 1992, p.58). Este precepto jurídico sirvió al Gobierno de Sanfuentes para perseguir a ácratas y antipatriotas; también se utilizó para exigir el traslado de algunos líderes obreros ${ }^{2}$ desde las provincias del norte del país. (Vicuña, p.111)

Esta persecución política justifica los resguardos tomados por el narrador rojiano al describir ciertos personajes de militancia libertaria, pues evidenciar las identidades de estos sujetos supondría exponerlos a los rigores de una ley que el abogado Carlos Vicuña ha catalogado de "infame y cruel" (p.111).

\section{Huellas, indicios y señales que conducen al escritor José Santos González Vera}

En los primeros capítulos de Sombras contra el muro se describe a Gutiérrez, un joven personaje que irrumpe en la peluquería de Teodoro y Víctor ${ }^{3}$ con el propósito de conseguir trabajo como aprendiz de barbero:

-Necesito aprender a trabajar, compañero -dice [Gutiérrez] a Teodoro. ¿No podría usted enseñarme a cortar el pelo y a afeitar?

$(\ldots)$

-Yo no puedo enseñarle nada -contesta el peluquero-, tengo que trabajar, pero usted puede estar aquí, ver cómo lo hago y procurar hacer lo mismo. Hágale empeño. Víctor anda en unas diligencias.

El joven agradece y contempla cómo Teodoro corta el pelo y afeita. (p.631)

La primera pista que invita a pensar que tras la ficción del aprendiz Gutiérrez se halla el escritor González Vera, se aprecia al atender el texto autobiográfico Cuando era muchacho (1951). En aquel relato el escritor señala que, al igual que el personaje rojiano, el desempleo no le dejó más opción que "entrar de aprendiz a una barbería situada en Calle San Pablo cerca de Brasil" (p.171). Esta convergencia laboral es relevante, en tanto evidencia que el autor González Vera y el aprendiz Gutiérrez, se vieron obligados a

\footnotetext{
${ }^{2}$ Entre los obreros desplazados, a razón de la Ley Jaramillo, se encuentra el diputado Luis Emilio Recabarren.

${ }^{3}$ Siguiendo las investigaciones historiográficas de Eduardo Godoy, el local descrito en Sombras contra el muro se condice con la 'Peluquería del Pueblo' dirigida por los ácratas Teodoro Brown Suárez y Víctor Garrido a comienzos del siglo XX. Es interesante subrayar esta sincronía onomástica, pues la ficción rojiana y el discurso histórico convergen al señalar que las peluquerías descritas estuvieron a cargo de sujetos cuyos nombres fueron Teodoro y Víctor.
} 
Pablo Fuentes R., En búsqueda de huellas, indicios y señales: una mirada meticulosa a tres personajes anarquistas de la tetralogía narrativa de Manuel Rojas - In search of traces, evidence and signs: a meticulous look at three anarchist characters from Manuel Rojas' narrative tetralogy, Revista Izquierdas, 25, octubre 2015, IDEA-USACH, ISSN 0718-5049, pp. 120-142

aprender un mismo oficio a causa de la cesantía.

Las confluencias entre el personaje rojiano y González Vera no se limitan al ámbito laboral, pues el sujeto novelesco coincide con el autor en gustos e intereses. El narrador de Sombras contra el muro evidencia la predilección del joven Gutiérrez por el mundo de las letras al señalar que, al igual que el escritor nacional, el aprendiz de barbero gusta de "la literatura, leer por lo menos (...) aunque para ello deba aprender a cortar el pelo y a afeitar" (p.630). Páginas más adelante, en la misma novela, el narrador vuelve a reiterar la afición de su personaje por las letras. Esta descripción es interesante, pues el narrador pormenoriza la predilección del joven Gutiérrez por la escritura de Pio Baroja:

Su pasión es la lectura (...) parece interesarse por los sentimientos que fluyen de todo ello, lo opuesto de uno y de otro, lo lógico y lo ilógico, las diferencias entre el sentimiento manifestado y el oculto. Lee más que nada, novelas, le gusta Baroja. (p.636)

En La oscura vida radiante las convergencias laborales y literarias se vuelven a repetir una vez que el joven Gutiérrez abandona el oficio de peluquero para emprender nuevos desafíos, encontrando sustento en la lustraduría de calzado. El narrador rojiano pormenoriza esta actividad de la siguiente manera: "el amigo Gutiérrez (...) a veces lustra los zapatos de un cliente y le dan su propina. Mientras, piensa en Zola” (p.704).

Al igual que el joven Gutiérrez, el escritor González Vera desempeñó otros oficios, entre ellos, el de lustrador; al respecto, el autor señala en Cuando era muchacho, su autobiografía, lo siguiente: "diéronme empleo de lustrador. (...) llegué a ser un lustrador bastante pasable. (...) uno quiere realizar bien su tarea, me encariñé con la lustraduría" (p.150). En el mismo texto el escritor se encarga de evidenciar su interés y predilección por la prosa de Émile Zola: "entre un empleo y otro íbame a la Biblioteca Nacional y leía cuanta obra hubiera de Zola, Balzac y France" (p.77).

Hasta esta parte, Sombras contra el muro y La oscura vida radiante evidencian algunas convergencias entre Gutiérrez, el personaje rojiano, y el escritor González Vera. Estas similitudes se suscitan en el ámbito laboral, pues ambos se desarrollaron como peluqueros y lustradores; en cuanto a gustos e intereses, ya que los dos presentan afición por el mundo de las letras; y finalmente, en relación a afinidades literarias, dado que el uno y el otro evidencian predilección por los mismos autores: Pio Baroja y Émile Zola.

$\mathrm{Si}$, a modo de detectives, continuamos tras la búsqueda de huellas e indicios notaremos que la escena final de Sombras contra el muro ofrece una señal que ayuda a develar el secreto que esconde el relato rojiano. En los episodios finales de la novela el joven Gutiérrez traba amistad con Aniceto Hevia. En relación a este vínculo amical algunos personajes de filiación libertaria consultan al protagonista respecto de las actividades que emprenderán para conmemorar el Primero de mayo: 
Pablo Fuentes R., En búsqueda de huellas, indicios y señales: una mirada meticulosa a tres personajes anarquistas de la tetralogía narrativa de Manuel Rojas - In search of traces, evidence and signs: a meticulous look at three anarchist characters from Manuel Rojas' narrative tetralogy, Revista Izquierdas, 25, octubre 2015, IDEA-USACH, ISSN 0718-5049, pp. 120-142

—QQué hacen los compañeros?

-Empiezan a preparar el Primero de Mayo.

- ¿Qué vas a hacer tú (Aniceto)?

- Creo que me encargarán los afiches y el manifiesto.

(...)

- ¿Y tu amigo Gutiérrez?

—Dice que va a sacar una revista manuscrita. (p.745)

Los indicios que vinculan a Gutiérrez con el escritor González Vera se evidencian al atender una entrevista concedida por Manuel Rojas a Antonio Avaria en 1968. En aquella oportunidad se consultó al autor de Hijo de ladrón respecto de algunos proyectos emprendidos durante la juventud, entre ellos Rojas destacó la creación de una revista manuscrita: “formamos el 'Grupo de los 7': era una revista escrita a mano por González Vera” (Citado por Fuenzalida, 2012, p.183).

Hasta esta parte, las confluencias entre el personaje rojiano y el escritor nacional se gestan en varios frentes: a nivel biográfico, en gustos e intereses literarios, y en relación a proyectos personales. Estas sincronías son relevantes, pues al sumarse unas con otras ayudan a develar el secreto que el narrador rojiano ha camuflado entre las páginas de la narración. Si bien las evidencias recabadas testifican a favor de nuestra tesis, aún hay muchos indicios por explorar y ratificar. En este sentido es prudente seguir las recomendaciones del experimentado detective Heredia de Ramón Díaz Eterovic: "tenemos sospechas, algunas declaraciones y unos cuantos papeles que no sirven para apretar el cuello a nadie. Debemos acumular más pruebas" (2005, p.190).

En La oscura vida radiante se describen algunos pormenores amorosos en la vida Gutiérrez. El aprendiz de peluquero se siente atraído por Silvia, una muchacha que no corresponde sus pretensiones. La distancia entre ambos personajes se incrementa una vez que Gutiérrez entabla una escena de celos tras hallar manchas de licor en la ropa de la jovencita: "no se conformó y empezó a vigilarla y a celarla y un día que Silvia llegó al alba con el vestido manchado de vino" (p.18).

La escena descrita en la novela rojiana ha sido escogida de los párrafos finales de la nouvelle Una mujer (1921) escrita por González Vera durante la juventud. En aquel relato el narrador gonzalezveriano señala: "llegó al amanecer trascendiendo a licor. Su hermosa bata blanca mostraba una infame mancha de vino" (1970, p.109).

En ambos relatos, La oscura vida radiante de Manuel Rojas y Una mujer de González Vera, el resultado de la escena de celos es un fuerte altercado. Es llamativo que el dialogo que el aprendiz Gutiérrez mantiene con su pretendida sea idéntico al pormenorizado, cinco décadas antes, por el narrador gonzalezveriano. Respecto de la novela de González Vera apuntamos:

- ¡Aprende imbécil! ¿Hasta cuándo quieres que te soporte? ¿Con qué derecho te ocupas de lo que haga? ¿Debo quererte a la fuerza? Es necesario que lo sepas. ¡Te aborrezco! Sí; te odio, te odio porque eres un egoísta, porque te falta no sé qué para ser hombre. No quiero oírte ni verte nunca más. ¡Qué cosas me ha dicho, Dios mío! (p.110). 
Pablo Fuentes R., En búsqueda de huellas, indicios y señales: una mirada meticulosa a tres personajes anarquistas de la tetralogía narrativa de Manuel Rojas - In search of traces, evidence and signs: a meticulous look at three anarchist characters from Manuel Rojas' narrative tetralogy, Revista Izquierdas, 25, octubre 2015, IDEA-USACH, ISSN 0718-5049, pp. 120-142

Por su parte, el narrador de La oscura vida radiante, destaca entre comillas el siguiente dialogo:

¡Aprende, imbécil! ¿Hasta cuándo quieres que te soporte? ¿Con qué derecho te preocupas de lo que haga? ¿Debo quererte a la fuerza...? Es necesario que lo sepas... ¡Te aborrezco! Sí. Te odio... te odio porque eres un egoísta, porque te falta no sé qué para ser un hombre. ¡No quiero oírte ni verte más, nunca más! ¡Qué cosas me ha dicho, Dios mío!. (p.18)

El vínculo entre La oscura vida radiante y Una mujer es evidente. De esta manera, a las convergencias biográficas, laborales, y de intereses literarios, se añaden confluencias que se explicitan a nivel de producción textual.

La intertextualidad es un recurso que se utiliza en más de una ocasión en La oscura vida radiante. Este procedimiento se evidencia una vez que el narrador rojiano señala: "Gutiérrez, continúa en su aprendizaje de hombre y de escritor" (p.230). Para comprender la relación entre el fragmento citado y la obra gonzalezveriana es necesario tener presente que el autor edita en 1960 el texto Aprendiz de hombre. De este modo, lo que hace el narrador de Rojas al señalar que el joven Gutiérrez continúa con su "aprendizaje de hombre" es aludir directamente el título de la obra gonzalezveriana.

En La oscura vida radiante, cuando Aniceto Hevia detalla a Gutiérrez sus dificultades para conseguir una habitación en la que vivir, el aprendiz de barbero responde lo siguiente:

-Oye, tengo una solución, aunque no sé si te gustará.

- Hombre, muchas gracias; díme.

- ¿Te gustaría vivir conmigo?

— ¿Contigo? ¿Cómo?

-En una pieza que podemos arrendar por ahí.

- ¿Y la cama?

-Yo llevaría una.

(...)

Si vivo contigo, ¿no impediré tu desarrollo?

José Santos Gutiérrez rio un instante con su risa silenciosa e inglesa. (pp. 31617)

La información que entrega el narrador rojiano es interesante, pues al señalar que Gutiérrez lleva por nombre 'José Santos', al igual que el escritor González Vera, añade similitudes onomásticas a las convergencias que ya hemos estudiado.

Volviendo a La oscura vida radiante, de acuerdo a José Santos Gutiérrez la única condición que limita sus opciones de compartir vivienda es no perder de vista los conventillos. Esta solicitud encuentra sentido al considerar que el personaje rojiano "escribía ya sobre los conventillos [y] publicaba trozos de sus trabajos" (p.320). Unos cuentos párrafos más adelante, Aniceto Hevia informa a los lectores acerca del trabajo de su amigo y compañero de habitación: 
Pablo Fuentes R., En búsqueda de huellas, indicios y señales: una mirada meticulosa a tres personajes anarquistas de la tetralogía narrativa de Manuel Rojas - In search of traces, evidence and signs: a meticulous look at three anarchist characters from Manuel Rojas' narrative tetralogy, Revista Izquierdas, 25, octubre 2015, IDEA-USACH, ISSN 0718-5049, pp. 120-142

El vecino Manuel ha dejado de hacer humitas y ha vuelto a fabricar cocinas de hojalata.

Esto dista mucho de alegrarme. Tal vez me desespere un tanto. Es inverosímil creer que en los días transcurridos se haya modificado su carácter.

Desde mañana cantará hasta reventar un sinnúmero de canciones empalagosas. Y cuando se le terminen los cantos, empezará a silbar... (pp. 320-1)

Efectivamente, el escritor nacional José Santos González Vera se interesó por la vida en los inmuebles populares. Aquella inclinación se traduce en la escritura de su novela El conventillo (1921). En aquel texto el narrador gonzalezveriano refiere, cinco décadas antes que la novela rojiana, la siguiente descripción:

El pescadero (...) fabrica cocinilla de hojalata. Esto dista de alegrarme. Tal vez me desespere un tanto. Es inverosímil creer que en los días transcurridos se haya modificado su carácter. Cantará desde la mañana un sinnúmero de canciones empalagosas. Cuando se le terminen los cantos empezará a silbar. (1970, p.38)

Este recurso de citación corrobora aquellas sospechas que indican que tras el personaje rojiano, José Santos Gutiérrez, se esconde la ficcionalización del escritor nacional González Vera. De este modo, las comillas incorporadas por el narrador al fragmento citado cumplen la función de intercalar un párrafo textual de El conventillo de González Vera en la ficción rojiana.

Unas cuantas páginas más adelante, en La oscura vida radiante, el recurso biográfico sirve al narrador para revelar algunos indicios que conducen al escritor de Alhué. Una vez que Aniceto Hevia y José Santos Gutiérrez han compartido vivienda por algún tiempo, el aprendiz de barbero evidencia sus deseos de abandonar la capital para trasladarse al sur del país, específicamente a las localidades de Temuco y Valdivia, donde ansía visitar a Gabriela, su amiga personal:

Pero Gutiérrez continuó:

— Tengo ganas de irme de Santiago. Nunca he llegado más allá de San Bernardo, hacia, el sur, y quiero conocerlo.

(...)

—iAdónde vas?

Iré primero a Temuco, a ver a Gabriela, mi amiga, y desde ahí me orientaré. Tal vez llegue a Valdivia. Me atrae mucho. (p.374)

Coincidentemente, González Vera indica en Cuando era muchacho que, cansado de la vida santiaguina, optó por trasladarse hasta el sur del país:

El deseo de viajar sin demora y establecerme en provincia no me dejó. Tutibeé largos días entre ir al norte o al sur. (...) Comprendí que para mí el paisaje tradicional era 
Pablo Fuentes R., En búsqueda de huellas, indicios y señales: una mirada meticulosa a tres personajes anarquistas de la tetralogía narrativa de Manuel Rojas - In search of traces, evidence and signs: a meticulous look at three anarchist characters from Manuel Rojas' narrative tetralogy, Revista Izquierdas, 25, octubre 2015, IDEA-USACH, ISSN 0718-5049, pp. 120-142

indispensable, y sin más resolví partir a donde encontrara árboles y pasto. (...) Elegí el sur. (pp.243-4)

Siguiendo el mismo texto autobiográfico, la 'amiga Gabriela' a la que hace referencias Gutiérrez, parece aludir a la poetisa Mistral. Recordemos que el escritor González Vera mantuvo una cercanísima relación con la Premio Nobel cuyos vínculos se forjaron en la ciudad de Temuco. Al respecto Hernán del Solar señala en el prólogo a Cuando era muchacho que "González Vera va a Temuco, donde estrecha amistad con Gabriela Mistral” (1996, p.10).

Estas simultaneidades de carácter geográfico y amical son relevantes, pues permiten sospechar, cada vez con más fundamento, que tras Gutiérrez se esconde la ficcionalización del escritor de Vidas mínimas.

Páginas más adelante, en La oscura vida radiante, Aniceto presta atención a la producción literaria de su amigo Gutiérrez, quien se encuentra desarrollando actividades afines en una revista llamada Númen ${ }^{4}$ :

Es la revista de la casa, Numen, ocho páginas; en este número hay algo de mi amigo Gutiérrez, un artículo breve, de carácter disquisitivo.

(...)

Aquí está:

La palabra sirve para orientar, unir y especular; pero no es posible efectuar nada sin recurrir a la acción. La palabra explica y juzga la realidad. La acción la crea y la expresa. En nuestro siglo hay un superávit de ideas; la realización de una pequeñísima parte de ellas, bastaría para crear una realidad nueva; una realidad que mejoraría absolutamente la vida de todos... (p.302)

El indicio que permiten vincular el fragmento citado con el escritor González Vera es la mención a revista Numen, pues el escritor nacional, además de publicar textos en aquella casa editorial, fue uno de sus fundadores junto a Juan Egaña (del Solar, 1996, p.10).

El texto que llama la atención de Aniceto Hevia, destacado entre comillas por el narrador rojiano, ha sido escogido del trabajo "Idea y figuras" publicado por González Vera en Numen el sábado 20 de septiembre de 1919. De acuerdo a Enrique Espinoza este mismo texto sirvió a Manuel Rojas, en una ceremonia en la Universidad de Chile, para rendir homenaje y reconocimiento a González Vera por la obtención del Premio Nacional de Literatura $^{5}(1986$, p.33-4).

La estrecha amistad entre Manuel Rojas y González Vera es bastante conocida. Julianne Clark, la tercera esposa de Rojas, señala que a ambos escritores los unía profunda amistad en la que además de su experiencia familiar, compartían un sentido del humor irónico, un inmenso cariño, la pasión por las letras y una postura política que no permitía claudicaciones" (2007, p.83). Tal vez, este profundo vinculo amical sirva para justificar la

\footnotetext{
${ }^{4}$ Numen fue un semanario de arte, sociología, actualidades y comercio.

${ }^{5}$ José Santos González Vera recibe el Premio Nacional de Literatura en el año 1950.
} 
Pablo Fuentes R., En búsqueda de huellas, indicios y señales: una mirada meticulosa a tres personajes anarquistas de la tetralogía narrativa de Manuel Rojas - In search of traces, evidence and signs: a meticulous look at three anarchist characters from Manuel Rojas' narrative tetralogy, Revista Izquierdas, 25, octubre 2015, IDEA-USACH, ISSN 0718-5049, pp. 120-142

presencia de González Vera, camuflado bajo el seudónimo de José Santos Gutiérrez, a lo largo de toda la tetralogía rojiana.

En definitiva, los indicios que se han señalado son suficientes para acreditar que, efectivamente, el narrador rojiano oculta al escritor González Veras tras la ficción del personaje Gutiérrez. A favor de esta presunción testifican antecedentes de índole: biográfica, afinidades literarias, sincronías onomásticas, precedentes familiares, concordancias geográficas, intertextual, de citación, y de producción textual.

\section{Huellas, indicios y señales que conducen al poeta José Domingo Gómez Rojas}

En Mejor que el vino Aniceto Hevia estrecha amistad con un joven poeta de escuálida figura. El narrador rojiano pormenoriza a este personaje señalando que, "llamado como el hermano de Aniceto, era estudiante de leyes" (p.856).

Para comprender la importancia de este indicio es necesario recordar que uno de los hermanos Hevia ${ }^{6}$ lleva por nombre Daniel. Esta información es relevante, pues establece vínculos onomásticos con el poeta José Domingo Gómez Rojas, quien firmó muchas de sus composiciones líricas, especialmente las publicadas en Selva lírica (1912) y la Pequeña antología (1917) del grupo los Diez, con el pseudónimo 'Daniel Vásquez'.

A la sincronía anterior se anexa la pormenorización académica del poeta. Para comprender la relevancia de esta información curricular se deben remitir las palabras de Germán Alburquerque, quien señala que Gómez Rojas, luego de "terminar sus Humanidades en el Liceo Manuel Barros Borgoño, ingresa a la Escuela de Derecho y al Instituto Pedagógico de la Universidad de Chile, estudiando Derecho y Castellano" (1999, p.153). De este modo, la formación universitaria de Gómez Rojas coincide con los estudios señalados en la ficción rojiana para el poeta Daniel. Estos antecedentes académicos se vuelven a reiterar en Sombras contra el muro una vez que el poeta insta a sus compañeros a asistir al velorio de Serrano:

En el momento en que se levantan para irse, entra Daniel (...) durante el trayecto encontró a los otros dos compañeros, los llevó con él. Viene a repetirse la trasnochada.

-No se vayan -suplica.

- Tenemos que levantarnos muy temprano -le dicen.

-Yo también; ustedes saben que estudio leyes. (p.684)

En Mejor que el vino el propio Aniceto Hevia se encarga de recordarnos los estudios de abogacía de Daniel. En aquella oportunidad el protagonista y el poeta idean algunos negocios para enfrentar las dificultades económicas. Dadas las complejidades que conlleva un buen proyecto, el poeta Daniel sugiere coludirse con delincuentes para robar el dinero de los clientes. Esta propuesta, que no es más que una humorada, suscita el rechazo de

\footnotetext{
${ }^{6}$ Los hermanos restantes de Aniceto son Exequiel y Joao.
} 
Pablo Fuentes R., En búsqueda de huellas, indicios y señales: una mirada meticulosa a tres personajes anarquistas de la tetralogía narrativa de Manuel Rojas - In search of traces, evidence and signs: a meticulous look at three anarchist characters from Manuel Rojas' narrative tetralogy, Revista Izquierdas, 25, octubre 2015, IDEA-USACH, ISSN 0718-5049, pp. 120-142

Aniceto, pues estima que es un comentario inapropiado para un estudiante de leyes:

El poeta, irritado con la idea de que alguien que no bebiera y a quien no le gustaran las mujeres se marchara con todo el dinero, tardó en reaccionar.

$(\ldots)$

- Por lo visto, no nos quedaría más remedio que contratar cogoteros. Cuando los tipos salieran a la calle, a la vuelta de la esquina... ¿Eh?

Esta vez el gesto fue de acogotar a alguien, gesto que Aniceto estimó poco apropiado para un estudiante de leyes. (p.857)

A las sincronías onomásticas y curriculares se añaden los lugares frecuentados por Daniel. Estos espacios son relevantes, pues evidencian paridades biográficas con el poeta Gómez Rojas. En Sombras contra el muro se indica que el joven vate hace su aparición en el Centro de Estudios Sociales Francisco Ferrer, centro cultural en el que convergen artesanos, obreros, estudiantes y conferencistas:

Daniel apareció una tarde en el Centro de Estudios Sociales Francisco Ferrer, muy joven, delgado, moreno, más bien bajo, limpio y casi elegante, aunque su elegancia consistía sólo en su ropa, hasta su corbata con nudo de mariposa y el bigotito que le hacía juego, eran de color negro. Fue anunciado, por un compañero, como un poeta revolucionario. (p. 637)

El escritor González Vera evidencia en Cuando era muchacho, texto autobiográfico, la fortuna que tuvo al entablar amistad con Gómez Rojas. Coincidentemente con la ficción rojiana el encuentro entre ambos escritores se concreta en el Centro de Estudios Sociales Francisco Ferrer": "almorzaba de prisa e íbame al Centro de Estudios Sociales Francisco Ferrer (...) habló un joven delgado, bajo, moreno, de ojos brillantes y voz emotiva. Narró cómo andando había llegado a Mendoza. Era el poeta José Domingo Gómez Rojas" (p.154).

El encuentro entre González Vera y Gómez Rojas es provechoso para nuestros intereses, pues demuestra que hay motivos fundados para sospechar que tras el personaje rojiano se esconde la ficcionalización del escritor Gómez Rojas; en segunda instancia esta información es significativa, en tanto sugiere una pormenorización prosopográfica de Gómez Rojas -“joven delgado, bajo, moreno, de ojos brillantes y voz emotiva" (p.154)que se condice con la descripción propuesta para el poeta Daniel en Mejor que el vino: “joven, delgado, moreno, más bien bajo" (p.637).

Una quinta pista que permite sospechar que tras la figura del poeta Daniel se esconde el escritor Gómez Rojas se evidencia al prestar atención a su descripción familiar.

\footnotetext{
${ }^{7}$ Las investigaciones historiográficas de Manuel de la Tierra han demostrado que aquel centro de estudios ofreció sus servicios culturales entre los años 1912 y 1916 en la ciudad de Santiago. Siguiendo las palabras del investigador en este espacio se discutía desde "la actualidad política hasta temas científicos, pasando por discusiones sindicales, divagaciones sobre Nietzsche, o las no escasas veladas al son de la poesía y la música libertaria" $(2009$, p.4).
} 
Pablo Fuentes R., En búsqueda de huellas, indicios y señales: una mirada meticulosa a tres personajes anarquistas de la tetralogía narrativa de Manuel Rojas - In search of traces, evidence and signs: a meticulous look at three anarchist characters from Manuel Rojas' narrative tetralogy, Revista Izquierdas, 25, octubre 2015, IDEA-USACH, ISSN 0718-5049, pp. 120-142

En Mejor que el vino se pormenoriza la prole del vate subrayando carencias y privaciones económicas: "[era] un hogar pobre, pobrísimo muchas veces, en que no hay el dinero indispensable para no morir de inanición y en que en ocasiones no hay comida ni calor y rara vez ropa limpia y libros" (p.856). El escritor Acevedo Hernández señala en el prólogo a Elegías (1913) que en cierta ocasión Gómez Rojas le convidó a pasar la noche junto a su familia. Aquella oportunidad le valió al dramaturgo para percatarse de las dificultades económicas del clan Gómez Rojas:

Nos hundimos en el arrabal. La calle San Diego, Victoria (...) llegamos. Penetramos por una gran puerta. Salió una señora, la madre del poeta.

- Mamá, este compañero viene a comer conmigo.

(...)

La señora lo llamó y le habló. Él se rió largamente.

-Mamá no se preocupe: traiga lo que haya en dos platos; repártalo a la manera salomónica.

- Y así fue como esa noche comí medio plato de frejoles en la casa del poeta que mejor supo en Chile evocar la eternidad. (1935, p.13)

Si bien las dificultades económicas descritas en la ficción rojiana concuerdan con las contrariedades señalas por Acevedo Hernández, es interesante prestar atención a las pretensiones pecuniarias del poeta. Al respecto la ficción rojiana señala que Daniel anhelaba las comodidades y lujos de la vida burguesa: "este poeta (...) soñaba con exquisitas viandas, finas ropas, elegantes y hermosas mujeres" (p.856). Acevedo Hernández concuerda, en el prólogo ya señalado, con el narrador rojiano al indicar que Gómez Rojas añoraba el confort de las clases acomodadas: "me habló de sus proyectos estupendos y me demostró que sería inmensamente rico cuando se le ocurriera. Un casamiento con una burguesa bastaría..." (p.13).

En Mejor que el vino el narrador de Rojas deja entrever ciertos pormenores que conducen hasta la producción lírica de Gómez Rojas:

Los versos (...) que cantaba a grito pelado a Luzbel, a Harmodio, (...) y a otros disconformes y amotinados seres fabulosos o heroicos, habrían sondado como cañonazo en los oídos de los hombres ya hechos, en tanto sonaban como música celestial en los tímpanos de los hijos de la sociedad futura. (p. 856)

Si realizamos una lectura meticulosa de los indicios que sugiere el relato rojiano, necesariamente nos encontraremos con la producción lírica gomezrojiana, específicamente con el poemario Rebeldías líricas publicado en 1912. De acuerdo a las investigaciones de Carlos Martínez, en aquellos entonces el poeta se hacía llamar 'Cohete', apodo con que lo bautizó el pintor Ricardo Gilbert ${ }^{8}$, a causa de su desenvoltura y énfasis en la declamación

\footnotetext{
${ }^{8}$ Ricardo Gilbert fue un pintor chileno perteneciente a la Generación del Trece. Cursó estudios de pintura en la Escuela de Bellas Artes con Fernando Álvarez de Sotomayor.
} 
Pablo Fuentes R., En búsqueda de huellas, indicios y señales: una mirada meticulosa a tres personajes anarquistas de la tetralogía narrativa de Manuel Rojas - In search of traces, evidence and signs: a meticulous look at three anarchist characters from Manuel Rojas' narrative tetralogy, Revista Izquierdas, 25, octubre 2015, IDEA-USACH, ISSN 0718-5049, pp. 120-142

(2009). En Sombras contra el muro, una vez que el poeta Daniel recita una de sus composiciones, se menciona este apodo:

Se paró detrás de la mesa, miró hacia el auditorio que lo observaba con curiosidad, (...) y leyó, con una voz que pareció increíble en un individuo de sus características, una larga y detonante tirada de versos. Las palabras, las rimas, las metáforas, resonaron, contra las paredes de adobe revestidas de apenas una capa de cal, como truenos.

—Este es el Poeta Cohete -murmuró un pintor. (pp.637-8)

Es llamativo que en Sombras contra el muro sea un pintor quien refiera el apodo del poeta Daniel. Posiblemente, mediante este recurso, el narrador rojiano ha querido referir a Ricardo Gilbert. En La oscura vida radiante este indicio se evidencia una vez que el narrador se decide a revelar el apellido de aquel pintor: "el poeta que el pintor Gilbert llamara El Poeta Cohete debido a la explosividad de sus versos" (p.45).

Las alusiones a Ricardo Gilbert cobran mayor sentido al realizar una estricta revisión de Rebeldías líricas. En aquel poemario, específicamente en "Renegación", Gómez Rojas apunta la siguiente dedicatoria: "A Ricardo Jilbert [sic] que rinde culto a Federico Nietzsche y comulga con Frank Brangroyn"” (p.32).

Los indicios que conducen a Ricardo Gilbert son significativos, pues las catálisis de las novelas estudiadas adquieren funciones informativas que dan cuenta de episodios biográficos de Gómez Rojas; a fin de cuentas, acontecimientos que la historiografía literaria olvidó registrar en sus manuales y compendios.

Andrés Sabella realiza un recorrido por la poesía de Gómez Rojas, identificando dos periodos claramente discernibles. Una primera etapa en que el poeta "expresa en Rebeldías líricas (...) el claro anhelo de la Redención. Su canción de entonces es de arcilla objetiva, llovida de rojo, con la tosca decoración de una sinceridad casta y valiente" (1937, p.11); más tarde, un segundo período en que el poeta "se enredó en la terrible espiral que danza frente al más allá (...) sediento de respuestas, se torció hacia Dios y sus palabras tuvieron como una porción de cielo tendida al fondo de su esencia" (p.12). El investigador Mario Rodríguez concuerda con Sabella, sosteniendo que en la lírica gomezrojiana se distinguen dos momentos: "la inicial, que corresponde a una rebeldía estética y, preferentemente, social (...) y una etapa final en la que el poeta abandona el terreno del cuerpo para entrar a uno radicalmente distinto, el terreno del alma..." (2000, p.10).

Esta mudanza en el temple poético de Gómez Rojas se deja sentir en la ficción rojiana, una vez que Aniceto Hevia y José Santos Gutiérrez analizan la producción textual de su amigo: "le contó que estaba cambiado (el poeta Daniel), por lo menos más cambiado que ellos: además de convertirse en un poeta místico, difuso, cambio profundo en un poeta lírico y tremendamente revolucionario, como había sido en un comienzo" (p.291).

En La oscura vida radiante el narrador de Rojas refiere estas variantes en la producción lírica de Daniel. En el fragmento que se cita a continuación, es necesario prestar

\footnotetext{
${ }^{9}$ Frank Brangroyn fue un artista anglo-gales, virtuoso grabador e ilustrador.
} 
Pablo Fuentes R., En búsqueda de huellas, indicios y señales: una mirada meticulosa a tres personajes anarquistas de la tetralogía narrativa de Manuel Rojas - In search of traces, evidence and signs: a meticulous look at three anarchist characters from Manuel Rojas' narrative tetralogy, Revista Izquierdas, 25, octubre 2015, IDEA-USACH, ISSN 0718-5049, pp. 120-142

atención a sus frases finales, aquellas que el narrador rojiano ha destacado entre comillas:

Olvidó (el poeta Daniel) los puños proletarios y las banderas rojas, que eran los temas de su juventud, y se entristeció y habló de Dios (...) pero después olvidó esto: tal vez hablar de Dios era una manera de hablar de la eternidad, algunos le llaman el Padre Eterno (...) y su alma se vertió hacia el pesimismo y el nihilismo: "La juventud, amor, lo que se quiere, ha de irse con nosotros: ¡Miserere! La belleza del mundo y lo que fuere, morirá en el futuro: ¡Miserere! La tierra misma lentamente muere con los astros lejanos: ¡Miserere! Y hasta quizás la muerte que nos hiere también tendrá su muerte: ¡Miserere!”. (p.292)

Si aceptamos la tarea de rastrear aquellas frases destacadas entre comillas por el narrador, hallaremos el poema "Miserere" publicado en Elegías. Los versos iniciales de tal composición coinciden con las líneas señaladas en la ficción rojiana:

La juventud, amor, lo que se quiere

ha de irse con nosotros. ¡Miserere!

La belleza del mundo y lo que fuere

morirá en el futuro. ¡Miserere!

La tierra misma lentamente muere

con los astros lejanos. ¡Miserere!

Y hasta quizá la muerte que nos hiere

también tendrá su muerte. ¡Miserere! (1935, p.139)

El narrador rojiano, al citar un fragmento poético e incorporarlo a la diégesis, confirma nuestras conjeturas. Efectivamente, José Domingo Gómez Rojas es quien se esconde tras la ficción del poeta Daniel en la tetralogía narrativa de Manuel Rojas, pues los fragmentos incorporados a la novela han sido seleccionados de la producción lírica gomezrojiana.

Si bien las pruebas reunidas son suficientes para corroborar nuestra hipótesis de trabajo, al igual que Razetti y Zelada en El hombre que pregunta (2002) de Díaz Eterovic, creemos necesario "efectuar otras investigaciones para confirmar lo que es tan evidente como la salida del sol” (p.182).

El narrador de La oscura vida radiante justifica el cambió de temple en la poesía de Daniel con la muerte de su hermano. Estas dificultades familiares explicarían el tránsito desde una lírica de corte anarquista a composiciones de orden místico: "el cambio de tono en su poesía, según confesaba él mismo, se debía a un drama familiar: un hermano suyo, llamado Mañungo, menor que él, había muerto un poco inesperadamente, y eso lo hirió de modo profundo" (p.291).

Si nos interiorizamos en la vida de Gómez Rojas apreciaremos que el fallecimiento de su hermano suscitó profundos cambios en su escritura. Andrés Sabella señala en Gómez Rojas: realidad y símbolo (1937) que tras el fallecimiento de su hermano el poeta compuso "Elegía por mi hermano", cuyos versos más significativos proponen: 
Pablo Fuentes R., En búsqueda de huellas, indicios y señales: una mirada meticulosa a tres personajes anarquistas de la tetralogía narrativa de Manuel Rojas - In search of traces, evidence and signs: a meticulous look at three anarchist characters from Manuel Rojas' narrative tetralogy, Revista Izquierdas, 25, octubre 2015, IDEA-USACH, ISSN 0718-5049, pp. 120-142

La carne de mi hermano tembló como aterida.

Mi madre, quebrantada, sollozó estremecida.

Fue un momento indecible de súplica a la vida.

¡Juventud de mi hermano para siempre dormida! (p.35)

Este testimonio es interesante, pues las sincronías entre el personaje rojiano y el poeta Gómez Rojas se extienden más allá del ámbito biográfico, onomástico, curricular y descriptivo, para suscitarse a nivel de producción textual.

Si fijamos la atención en algunos episodios de vida de Gómez Rojas será imprescindible prestar atención a su encarcelamiento, locura y muerte. Este dramático acápite en la vida del escritor es fundamental, pues señala un martirio que, en palabras de Mario Rodríguez, el poeta "no fue capaz de resistir por su índole de hombre sensible y fino" (p.6). El encarcelamiento de Gómez Rojas se suscita a causa de su militancia anarquista, en razón de tal aprisionamiento Germán Albuquerque indica:

[Gómez Rojas era] uno de los líderes del vigoroso movimiento estudiantil que hacia el año 1920 se erguía como un actor relevante de la escena nacional. (...) El Gobierno de Sanfuentes ordenó perseguir a los grupos anarquistas "subversivos" con lo cual algunos dirigentes de la Industrial Workers of the World (IWW) cayeron presos. Entre ellos, estaba José Domingo. (p.153)

En La oscura vida radiante el narrador aclara que Daniel comulga con el anarquismo. Está militancia ácrata, sumada a su participación en la IWW, son antecedentes suficientes para que la ley Jaramillo decida a hacer presa en el poeta:

Daniel (...) estaba preso también, aquél no le creyó:

— ¿Por qué va a estar preso? Es radical y los radicales acaban de ganar una elección presidencial.

- ¿Quién te ha dicho que Daniel Vásquez es radical?

-Así lo creo desde hace tiempo.

—Estás equivocado: Daniel es de la I.W.W.

(...)

— ¿Daniel era, es, de los Trabajadores Industriales del Mundo? ¿Anarcosindicalista ?

-Por supuesto, uno de los secretarios de la directiva, junto con Juan.

— ¿Y por qué está preso?

(...)

La Policía de Investigaciones hizo lo que ha hecho muchas veces: urdió un complot terrorista, con cartuchos de dinamita y todo, y lo colocó en la I.W.W. Están presos todos, Daniel entre ellos. (p.373)

El dialogo anterior revela un cruce biográfico entre el personaje rojiano y Gómez Rojas, pues tanto el uno como el otro, son arrestados, encarcelados y muertos a causa de su militancia ácrata. 
Pablo Fuentes R., En búsqueda de huellas, indicios y señales: una mirada meticulosa a tres personajes anarquistas de la tetralogía narrativa de Manuel Rojas - In search of traces, evidence and signs: a meticulous look at three anarchist characters from Manuel Rojas' narrative tetralogy, Revista Izquierdas, 25, octubre 2015, IDEA-USACH, ISSN 0718-5049, pp. 120-142

En definitiva, los indicios que se hemos señalado son suficientes para acreditar que, efectivamente, el narrador rojiano oculta al poeta José Domingo Gómez Rojas tras la ficción del poeta Daniel. A favor de esta presunción testifican antecedentes de índole: onomástico, curricular, familiar, espacial, descriptivo, de producción textual, y afinidades políticas.

\section{Huellas, indicios y señales que conducen al médico Juan Gandulfo}

Juan Gandulfo Guerra nació en Los Vilos el 16 de julio de 1895 en una familia acomodada. Esta ascendencia no fue impedimento para desarrollar un acercamiento leal hacia las clases más desposeídas. De acuerdo a Fabián Pavez la preocupación de Gandulfo por los sectores populares se incrementó durante la juventud tras la lectura de los principales teóricos del anarquismo: Kropotkin y Malatesta (2009, p.431).

En 1919 la sensibilidad libertaria de Gandulfo se concretiza en críticas al gobierno del Presidente Juan Luis Sanfuentes, al que acusó de incapacidad absoluta para resolver los problemas nacionales. Aquellas protestas le costaron a Gandulfo varios meses en la cárcel.

Esta detención es una prueba fehaciente de la Ley Jaramillo, disposición jurídica que justifica los resguardos tomados por el narrador rojiano al preferir camuflar a Gandulfo entre las páginas de la narración. Dado este recurso narrativo es necesario pesquisar huellas, indicios y señales que conduzcan hasta la identidad del médico libertario. Para conseguir este propósito señalamos una primera pista de orden onomástico, pues en las novelas rojianas se pormenoriza un personaje que comparte un mismo nombre con Gandulfo: don Juan.

A esta sincronía onomástica se añaden indicios de orden curricular, pues tanto Gandulfo como el personaje rojiano desarrollan labores médicas. Al respecto, en Sombras contra el muro, el narrador pormenoriza las funciones de don Juan señalando lo siguiente:

Este otro Juan no quiere ser sino lo que es, médico, y como médico, cirujano (...) y es cirujano no porque le guste la sangre, sino porque es un trabajo minucioso y serio. (p.616)

Juan, que ha visto durante sus años de estudiante y de médico, en la consulta, en las salas de los hospitales, en las postas de la Asistencia Pública (...) a innumerables seres, y que lleva en su mente algo así como un registro de actitudes, movimientos, tonos, quejidos. (p. 617)

A su vez, en La oscura vida radiante, se describe a don Juan mientras diagnostica un paciente:

Todas las mañanas estaba al borde de la sangre, era cirujano, la cuidaba y la retenía, que no se pierda, y todas las tardes al borde del dolor, en la consulta. "Don Juan, me duele aquí." (...) todas aquellas mañanas y en todas aquellas tardes debía luchar contra la sangre y contra la enfermedad, contra lo imprevisible de ésta y el ímpetu de aquélla. (p.166) 
Pablo Fuentes R., En búsqueda de huellas, indicios y señales: una mirada meticulosa a tres personajes anarquistas de la tetralogía narrativa de Manuel Rojas - In search of traces, evidence and signs: a meticulous look at three anarchist characters from Manuel Rojas' narrative tetralogy, Revista Izquierdas, 25, octubre 2015, IDEA-USACH, ISSN 0718-5049, pp. 120-142

Esta información coincide con la biografía de Juan Gandulfo, quien también desarrolló labores médicas, específicamente en cirugía. De acuerdo al doctor Ricardo Zalaquett, el galeno anarquista comenzó su carrera profesional en el "Hospital Manuel Arriarán, y de la Asistencia Pública y luego de la Clínica del Profesor Lucas Sierra, en el viejo Hospital San Vicente" (2005, p.377). Fabián Pavez completa esta información apuntando que Gandulfo se interesó especialmente por la cirugía infantil, plástica y ortopedia (p.431).

Sorprende que el poeta Pablo Neruda colabore en esta tarea de identificación de indicios, ya que en sus memorias, Confieso que he vivido (1974), entrega información que conduce hasta Juan Gandulfo. En este texto el vate rememora un pasaje de juventud en que Gandulfo le brindó auxilio médico:

Juan Gandulfo (...) me trataba como si fuera un niño, que en realidad lo era. Una vez que llegué tarde a su estudio, para una consulta médica, me miró ceñudo y me dijo: “¿Por qué no vino a la hora? Hay otros pacientes que esperan”. "No sabía qué hora era", le respondí. "Tome para que la sepa la próxima vez", me dijo, y sacó su reloj del chaleco y me lo entregó de regalo. (1999, p.47)

Esta pista es relevante, en tanto evidencia confluencias que se suscitan en el ámbito curricular entre el personaje rojiano y el médico Gandulfo. Para completar esta información es necesario interiorizarse en la trayectoria médica y laboral del galeno. En razón de este propósito citamos un fragmento de La oscura vida radiante en que se pormenoriza a don Juan desarrollando sus labores en la Casa de Orates:

- Bueno, usted sabe que don Juan es médico del manicomio y amigo de los médicos que trabajan ahí, y como el juez pidió un informe médico-legal y un dictamen sobre si Miguel estaba loco o no y don Juan era también amigo y compañero de estudios del médico que tenía que examinar a mi hermano, el cabro resultó con sus facultades mentales perturbadas. (p.149)

Si se contrapone la información que entrega la novela rojiana con lo señalado por el doctor Agustín Inostroza, se puede apreciar que, efectivamente, Juan Gandulfo desempeñó funciones de cirugía en el manicomio: "un concurso de internado nos reúne nuevamente en la Casa de Orates. En él ocupa (Gandulfo) los primeros lugares, entrando de lleno al desempeño de sus funciones médicas" (Citado por Carrasco, 1957, p.12). En Juan Gandulfo Guerra: homenaje de sus amigos (1957) se reiteran las labores desarrolladas por el galeno en el recinto psiquiátrico: "fue un buen estudiante, desempeñó ayudantía en Biología y en higiene y fue interno de la Casa de Orates” (Carrasco, p.32).

Este pormenorización curricular es relevante, pues sustenta las conjeturas que sugieren que tras don Juan, el personaje rojiano, se halla el medico Juan Gandulfo. Continuando con esta óptica, en La oscura vida radiante se indica que el personaje rojiano no sólo desarrolla labores médicas en hospitales, la asistencia pública, y el manicomio; sino 
Pablo Fuentes R., En búsqueda de huellas, indicios y señales: una mirada meticulosa a tres personajes anarquistas de la tetralogía narrativa de Manuel Rojas - In search of traces, evidence and signs: a meticulous look at three anarchist characters from Manuel Rojas' narrative tetralogy, Revista Izquierdas, 25, octubre 2015, IDEA-USACH, ISSN 0718-5049, pp. 120-142

que también se desempeñó en la cárcel:

Había asistido a innumerable gente en la cárcel, donde fue médico, en el hospital y en el manicomio y de cada uno aprendió los recursos que tenía contra la pobreza, contra la policía, contra el hambre; nadie podía mentirle, nadie podía engañarle, así como él no mentía ni engañaba a nadie. (p.166)

Al contrastar lo descrito para el personaje rojiano con la vida del médico Gandulfo se aprecian confluencias importantes. Ciertamente, Juan Gandulfo estuvo privado de libertad en dos ocasiones, en una primera oportunidad, como ya se dijo, a causa de criticar el gobierno de Sanfuentes; y luego, en 1920, a razón de "protestar por el estado de las cosas y propiciar el entendimiento entre obreros" (Zalaquett, p.380). Esta segunda ocasión fue aprovechada por Gandulfo para desarrollar diversos proyectos, según González Vera, durante su reclusión el médico anarquista no se echó a morir, le bastaron unas vueltas por las galerías penitenciarias para:

Apreciar el aspecto de los penados y comenzar el examen de cada uno. Curó a cuentos pudo, les organizó una biblioteca, hizo instalar un consultorio, consiguió que los de mejor conducta pudieran recibir en privado a sus mujeres (...) impuso medidas de profilaxia y encontró trabajo para todas sus horas. (1951, p.308)

De este modo, a nivel curricular, las confluencias entre el personaje rojiano y el médico Juan Gandulfo son cada vez más sólidas, pues ambos desarrollan labores de cirugía en hospitales y la asistencia pública, siendo más específicos, en la Casa de Orates y la cárcel.

Ricardo Zalaquett señala que Juan Gandulfo, a pesar de sus espléndidos antecedentes académicos y laborales, tuvo dificultades al iniciar su carrera médica, pues intentó trabajar en varios hospitales, y en todos, a su sólo nombre, le cerraban las puertas (p.380). El abogado Carlos Vicuña explica este recelo, indicando que Gandulfo era sindicado subversivo y anarquista, por lo que su apellido era argumento suficiente para estimarlo "un crimen irreparable" (p.129).

Dado que Juan Gandulfo no escribió ningún texto en el que reconociera abiertamente su militancia ácrata, sus más cercanos tuvieron que asumir esta tarea de filiación política. Así lo hizo Armando Alonso en Nota biográfica sobre Juan Gandulfo (1932), señalando que:

Gandulfo ha sido siempre anarquista; no ha abandonado nunca su credo anarquista (...) Me consta, aun cuando seguramente me faltan méritos para apreciar el pensamiento, el sentimiento y la obra anarquista (...) Gandulfo pudo no etiquetarse nunca de anarquista; pero lo era por antonomasia, yo lo sentí, a cada instante, feliz de serlo y creo que, en esa convicción, y en esa felicidad radica gran parte de su triunfo integral como médico. (Citado por Pavez, p.431) 
Pablo Fuentes R., En búsqueda de huellas, indicios y señales: una mirada meticulosa a tres personajes anarquistas de la tetralogía narrativa de Manuel Rojas - In search of traces, evidence and signs: a meticulous look at three anarchist characters from Manuel Rojas' narrative tetralogy, Revista Izquierdas, 25, octubre 2015, IDEA-USACH, ISSN 0718-5049, pp. 120-142

Pablo Neruda tuvo la oportunidad de conocer a Gandulfo en tanto desempeñaba labores en la dirigencia estudiantil en la Federación de estudiantes de la Universidad de Chile. Al respecto el poeta indica que el médico era el más formidable líder "temido por su atrevida concepción política y valentía a toda prueba" (p.47).

Obviamente la sensibilidad ácrata de Gandulfo es una arista que el narrador rojiano no dejaría pasar por alto. Tal vez por ello, en Sombras contra el muro, se menciona la responsabilidad que suscita en don Juan el dolor y las necesidades del proletariado:

Es cirujano no porque le guste la sangre, sino porque es un trabajo minucioso y serio y porque alguien está sufriendo y necesita, rápidamente, alivio y defensa, y cuando los ayudantes ponen ante él, ya anestesiado, a la mujer o al hombre, siente que ese ser, que llega dormido a sus manos, confía en él y se entrega a él. (p.616)

Esta fuerte sensibilidad social es un indicio relevante al momento de evidenciar pruebas que demuestren que el médico Gandulfo es quien se esconde tras la ficción de don Juan. Si analizamos los estudios publicados por Gandulfo, puntualmente Tratamiento quirúrgico del mal de Pott (1931), apreciaremos en la introducción de este artículo científico la preocupación del galeno por las carencias higiénicas y hospitalarias con las que debe lidiar el proletariado:

En Chile, vemos que el mal de Pott hace estragos en el pueblo (...) no hay sanatorios donde hacerlo y la pobreza obliga al que tiene tuberculosis vertebral a reanudar sus obligaciones en un plazo breve.

(...)

Las camas son tan escasas y los enfermos tan numerosos que la intervención se hace cada día más imperativa, a pesar de las reservas a que obliga su resultado, según se desprende de las observaciones hechas en los hospitales R. del Río y M. Arriarán de Santiago. (1931, p.10)

La preocupación de Gandulfo por los sectores más carenciados concuerda con los intereses de don Juan en la ficción rojiana una vez que invita, en Sombras contra el muro, a colegas y estudiantes a participar en la realización de un policlínico popular:

Pueden abrir una clínica para los camaradas y obreros o trabajadores más pobres, en un barrio pobre, todo gratis, sí, tengo amigos que me ayudarían a atenderla, estudiantes de los últimos años y hasta médicos, estupendo, doctor, voy a hablar con ellos, qué te parece. (p.618)

Páginas más adelante, en la misma novela, el narrador vuelve a mencionar el proyecto hospitalario liderado por don Juan:

-Estamos organizando el policlínico, compañero Pinto, creo que dentro de unos meses empezará a funcionar. 
Pablo Fuentes R., En búsqueda de huellas, indicios y señales: una mirada meticulosa a tres personajes anarquistas de la tetralogía narrativa de Manuel Rojas - In search of traces, evidence and signs: a meticulous look at three anarchist characters from Manuel Rojas' narrative tetralogy, Revista Izquierdas, 25, octubre 2015, IDEA-USACH, ISSN 0718-5049, pp. 120-142

-Eso me gusta, don Juan. Hay que hacer obra práctica. Inaugurar policlínicos, poner bombas, échele para adelante.

Unos miran y saben para dónde empujan, a otros no les importa para dónde sea, con tal de empujar, mientras uno empuje, está vivo. (p.711)

Este policlínico popular es de relevancia para nuestros intereses, pues entrega indicios que ayudan a certificar que quien se esconde tras la ficción del personaje rojiano es el médico Juan Gandulfo. Al corroborar esta información apreciamos que, realmente, el médico anarquista gestionó un policlínico para atender a obreros y sus familias. De acuerdo a las investigaciones de Fabián Pavez, a fines de 1922 el proyecto gozaba de un éxito halagador, reuniéndose más de mil pesos para su instalación, además de instrumental quirúrgico e inmobiliario hospitalario. Siguiendo esta investigación señalamos que luego de la trágica muerte del cirujano anarquista el proyecto cambió de nombre a "Policlínico Obrero Juan Gandulfo Guerra", en honor y reconocimiento a la labor de su fundador (p.430).

En La oscura vida radiante se describe la visita de Aniceto Hevia a la consulta de don Juan. En esta escena es necesario prestar atención a la pormenorización del delantal que viste el galeno, específicamente a las letras bordadas en lanilla azul que decoran el bolsillo superior de la prenda:

Antes, visitó (Aniceto), durante la semana y al final de su consulta, a don Juan. “¿Cómo te ha ido? Cuéntame”. Se sacó el delantal, un delantal muy blanco que tenía a la izquierda un bolsillo sobre cuya boca se veían sus iniciales, "J. G.", hechas con una lanilla azul. (p.185)

Las iniciales "J.G" que decoran el delantal del médico son señales que certifican, de modo manifiesto, que Juan Gandulfo se esconde tras la ficción del personaje rojiano. Aunque esta pista otorga solidez a nuestra conjetura, es necesario continuar tras la búsqueda de nuevos indicios.

Hasta esta parte, hemos fijado la atención en confluencias que se suscitan entre el personaje rojiano y el médico Gandulfo en el ámbito onomástico, curricular, laboral, político y en la gestión de proyectos sanitarios. A estas sincronías es necesario añadir aspectos descriptivos, especialmente los rasgos físicos que se pormenorizan para el médico. Al respecto, en Sombras contra el muro, se señala la siguiente descripción para don Juan:

Juan, moreno, bajo, un poquito regordete, de alta frente, casi calvo ya - "recuerden que los sátiros son calvos", decía, defendiéndose- y con los ojos que parecían no mirar sino examinar, ojos penetrantes, y llenos de luz, ser lleno de alegría y también de pensamiento, lleno de acción al mismo tiempo que de reflexión. (p.166)

Quienes tuvieron la fortuna de conocer a Juan Gandulfo están en condiciones de certificar que la pormenorización que se indica para el personaje rojiano se condice con el 
Pablo Fuentes R., En búsqueda de huellas, indicios y señales: una mirada meticulosa a tres personajes anarquistas de la tetralogía narrativa de Manuel Rojas - In search of traces, evidence and signs: a meticulous look at three anarchist characters from Manuel Rojas' narrative tetralogy, Revista Izquierdas, 25, octubre 2015, IDEA-USACH, ISSN 0718-5049, pp. 120-142

aspecto del médico. Por ejemplo, Pablo Neruda acredita que el cirujano anarquista, al igual que don Juan en la ficción rojiana, se caracteriza por su calvicie y baja contextura: "Juan Gandulfo era pequeño de estatura, redondo de cara y prematuramente calvo" (p.47). A su vez, Alejandro Reyes, colega de Gandulfo, acredita que la calvicie era una de las particularidades del cirujano: "tenía Juan (...) el cráneo amplio, redondo (...) de frente despejada, los ojos oscuros de mirada penetrante y fresca" (en Carrasco, p.13). González Vera también puede garantizar que, además de la calvicie, la baja estatura fue característica de Gandulfo: "era un estudiante pequeño, carirredondo, de voz ronca" (1951, p.133).

Un último indicio que vincula al personaje rojiano con el médico Gandulfo se presenta al atender las coordenadas que conducen hasta su vivienda. En La oscura vida radiante el narrador indica que don Juan habita en Santiago, específicamente en calle San Isidro: "una paz muy grande empieza a extenderse por la ciudad y por la calle San Isidro, donde vive Juan: se oye el taconeo de las personas que han salido ya de sus trabajos" (p.194).

Si prestamos atención a la nota que publica El Mercurio para informar de la trágica muerte de Juan Gandulfo ${ }^{10}$, notaremos que las coordenadas señaladas para la vivienda del médico coincide con la ubicación pormenorizada por el narrador rojiano para su personaje:

La mañana del domingo 27 de diciembre de 1931, el Dr. Juan Gandulfo fue recogido de su casa de la calle Londres por sus amigos, el profesor de inglés y filosofía don Eduardo Barrenechea y el Dr. Juan Garafulic, para dirigirse a Viña del Mar. (...) Minutos después de las 10 de la mañana, en la Vinilla, kilómetros antes de Casablanca, el Studebaker se volcó. Gandulfo murió instantáneamente. (Citado por Zalaquett, p.376)

Aunque la ficción rojiana indica calle San Isidro para la habitación de don Juan, mientras que el matutino señala calle Londres para Gandulfo, al rastrear tales coordenadas en el mapa de Santiago se aprecia que ambas avenidas son paralelas, y se distancian por sólo tres cuadras. De hecho, ambas avenidas forman parte de un mismo espacio, el "Barrio San Isidro".

Por consiguiente, y considerando lo que se ha expuesto, estamos en condiciones de sostener que los indicios de orden onomástico, curricular, laboral, político, de gestión hospitalaria, descriptivos, y urbanísticos que se han señalado, son suficientes para acreditar que quien se esconde tras don Juan en la ficción rojiana es el médico Juan Gandulfo Guerra.

\footnotetext{
${ }^{10}$ Juan Gandulfo fallece tras un accidente automovilístico en las cercanías de Casablanca, Valparaíso.
} 
Pablo Fuentes R., En búsqueda de huellas, indicios y señales: una mirada meticulosa a tres personajes anarquistas de la tetralogía narrativa de Manuel Rojas - In search of traces, evidence and signs: a meticulous look at three anarchist characters from Manuel Rojas' narrative tetralogy, Revista Izquierdas, 25, octubre 2015, IDEA-USACH, ISSN 0718-5049, pp. 120-142

\section{Conclusión}

Debido a las restricciones impuestas por la Ley Jaramillo, el narrador rojiano decide camuflar las identidades de aquellos sujetos que se atrevieron a transgredir los límites trazados por el gobierno del Presidente Juan Luis Sanfuentes. Para mantener a salvo a quienes escogieron desestabilizar el poder, el narrador rojiano procede a encubrir las identidades de aquellos sujetos subversivos que ha representado en su relato. Este procedimiento garantiza al escritor González Vera, el poeta Gómez Rojas, y el médico Juan Gandulfo que sus proyectos e intereses se mantendrán a salvo de las restricciones de la Ley Jaramillo. Si el narrador rojiano no tomase resguardo alguno, y apuntase estos nombres en la diégesis, su relato supondría una denuncia en los aparatos de orden y seguridad.

Las previsiones asumidas para José Santos González Vera se justifican al considerar su militancia anarquista. Dada esta sensibilidad política, el narrador camufla al escritor tras el pseudónimo 'Gutiérrez'; sin embargo, entrega una serie de pistas de índole biográfica, literaria, onomástica, familiar, geográfica, textual, de citación e intertextualidad que al ser rastreadas conducen hasta la identidad del escritor nacional.

La situación es similar para José Domingo Gómez Rojas cuya militancia en la I.W.W., el brazo sindical del anarquismo, fue causal suficiente para que la Ley Jaramillo hiciese presa en el poeta. Lamentablemente, de las infamias cometidas por el poder nos hablan el encarcelamiento, locura y muerte del joven vate.

No obstante el narrador rojiano toma resguardos al momento de señalar episodios de vida de Gómez Rojas, entrega una serie de pistas onomásticas, curriculares, familiares, espaciales, descriptivas, textuales, y políticas que al ser pesquisadas e interpretadas conducen hasta el autor de Rebeldías líricas.

Finalmente, la militancia anarquista del médico Juan Gandulfo justifica los resguardos asumidos por el narrador rojiano al apuntar sus intereses y proyectos. Si bien el médico se encuentra oculto entre las páginas de la tetralogía rojiana, el narrador entrega una serie de huellas de índole onomástica, curricular, laboral, política, de gestión hospitalaria, descriptivos, y urbanísticos que conducen hasta el médico libertario.

Considerando todo lo que se ha expuesto, estimamos que Ricardo Piglia acierta al sugerir una lectura a modo de detectives, pues este método de estudio nos ha servido para pesquisar huellas, indicios y señales capaces de develar la identidades de aquellos sujetos que el narrador rojiano ha preferido camuflar y mantener ocultos entre las páginas de la narración; en otras palabras, este procedimiento lector nos ha valido para revelar el secreto que el narrador rojiano ha cifrado entre los materiales político e ideológicos del relato.

Recibido: 23 enero $2015 \quad$ Aceptado: 14 junio 2015 


\section{Bibliografía}

Albuquerque, G. (1999). Gómez Rojas, el Cristo de los poetas. Derecho y humanidades 7 , 153-168.

Alonso, A. (1932). Notas biográficas sobre Juan Gandulfo. Santiago: Sociedad médica de Chile.

Carrasco, M. (1957). Juan Gandulfo Guerra: homenaje de sus amigos. Santiago: Editorial no identificada.

Clark, J. (2007). Y nunca te he de olvidar... memorias de mi vida junto a Manuel Rojas. Santiago: Catalonia.

del Solar, H. (1996). José Santos González Vera [prólogo]. Cuando era muchacho. Santiago: Universitaria. 9-13.

de la Tierra, Manuel. (2009, Octubre). La pedagogía libertaria. Su urgencia, sus ideas elementales y algunos apuntes para la historia de sus experiencias en la región chilena. El Surco, 8.

Díaz Eterovic, R. (2002). El hombre que pregunta. Santiago: Lom.

---. (2005). A la sombra del dinero. Santiago: Lom.

Espinoza, E. (1982). José Santos González Vera. Clásicos del humor. Santiago: Andrés Bello.

Fuenzalida, D. (2012). Conversaciones con Manuel Rojas. Entrevistas 1928-1972. Santiago: Zig-zag.

Gandulfo, J. (1931). Tratamiento quirúrgico del mal de Pott. Santiago: Universo.

Godoy, E. (2011, Abril). Teodoro Brown y Víctor Garrido: la historia de dos peluqueros anarquista a comienzos del siglo XX. El Surco, 6.

Gómez Rojas, J. (1935). Elegías. Nascimiento: Santiago.

---. (1940). Rebeldías líricas. Ercilla: Santiago.

González Vera, J. (1951). Cuando era muchacho. Santiago: Nascimiento.

---. (1960). Aprendiz de hombre. Santiago: Zig-zag.

---. (1970). El conventillo. Vidas mininas. Santiago: Nascimiento.19-70.

---. (1970). Una mujer. Vidas mininas. Santiago: Nascimiento.71-110.

Martínez, C. (2009). José Domingo Gómez Rojas. Recuperado de http://www.espartako.cl/poetas/gomez/biogomez.html

Neruda, P. (1999). Confieso que he vivido. Madrid: Millenium.

Pavez, F. (2009). Experiencias autogestionarias en salud: El legado de Gandulfo en La Hoja Sanitaria y el Policlínico de la Organización Sindical Industrial Workers of the World (1923-1942). Revista médica de Chile, 137(3), 426-432.

Piglia, R. (2001). Crítica y ficción. Barcelona: Anagrama.

Rodríguez, M. (2002). La poesía de José Domingo Rojas [prólogo]. Elegías. Concepción: Universidad de Concepción.

Rojas, M. (1974). Hijo de ladrón. Obras escogidas. Tomo I. Santiago: Zig-zag. 379-601.

---. (1974). Sombras contra el muro. Obras escogidas. Tomo II. Santiago: Zig-zag. 601-747 
Pablo Fuentes R., En búsqueda de huellas, indicios y señales: una mirada meticulosa a tres personajes anarquistas de la tetralogía narrativa de Manuel Rojas - In search of traces, evidence and signs: a meticulous look at three anarchist characters from Manuel Rojas' narrative tetralogy, Revista Izquierdas, 25, octubre 2015, IDEA-USACH, ISSN 0718-5049, pp. 120-142

---. (1974). Mejor que el vino. Obras escogidas. Tomo II. Santiago: Zig-zag. 747-939.

---. (2008). La oscura vida radiante. Santiago: Lom.

---. (2008). Antología autobiográfica. Santiago: Lom.

Sabella, A. (1937). Gómez Rojas: realidad y símbolo. Santiago: Cóndor.

Vicuña, C. (2002). La tiranía en Chile: libro escrito en el destierro. Santiago: Lom.

Vitale, L. (1992). Interpretación marxista de la historia de Chile. Tomo V. Santiago: Lom.

Zalaquett, R. (2005). ¡Siembra, juventud! la tierra es propicia, el momento es único: No es Neruda sino Gandulfo, el cirujano. Revista médica de Chile, 133(3), 376-382. 